\title{
Qualidade do ar: tecnologia calma, visualização de dados e engajamento cidadão
}

Air quality: calm technology, data visualization and citizen engagement

PINHEIRO, Mauro; Dr.; Universidade Federal do Espírito Santo (Ufes)

mauro.pinheiro@ufes.br

TINOCO, Daniela; Graduanda; Escola Superior de Desenho Industrial (Esdi/Uerj)

daniela_jt@rocketmail.com

\section{Resumo}

Este artigo apresenta o desenvolvimento de um sistema de visualização de dados relativos à qualidade do ar na cidade do Rio de Janeiro. O projeto fundamenta-se na proposta de Tecnologia Calma de Weiser e Brown (1996), e o sistema de visualização de dados desenvolvido segue os princípios dos Sistemas de Informação Ambiente. A visualização de dados é tratada como ferramenta de empoderamento, numa perspectiva de propiciar a discussão e o engajamento do cidadão no contexto das Cidades Inteligentes. O projeto utiliza uma metodologia orientada pela experimentação e prototipação, mantendo ciclos sucessivos em que cada protótipo produzido é analisado criticamente, gerando subsídios para a versão seguinte. Parte-se de uma discussão sobre os conceitos de Tecnologia Calma, Sistemas de Informação Ambiente e Cidades Inteligentes, para em seguida descrever o desenvolvimento do sistema de visualização de dados, discriminando os processos envolvidos, tecnologias empregadas, os partidos adotados e resultados obtidos.

Palavras Chave: visualização de dados; qualidade do ar; tecnologia calma.

\section{Abstract}

This article presents the development of a data visualization system depicting air quality in the city of Rio de Janeiro. The project is based on the concept of Calm Technology from Weiser and Brown (1996), and the data visualization system developed follows the principles of Ambient Information Systems. Data visualization is treated as an empowerment tool, aiming to foster citizen engagement and participation, in the context of Smart Cities. The project uses a design methodology which is guided by experimentation and prototyping, maintaining successive cycles in which each produced prototype is analyzed, generating subsidies for the next version. The article starts with a discussion about the general concepts of Calm Tencology, Ambient Information Systems and Smart Cities. Next, we describe the development of the data visualization system, describing the processes involved, the technologies employed and the results achieved.

Keywords: data visualization; air quality; calm technology. 


\section{Introdução}

Nas definições sobre " cidades inteligentes " sobressai com freqüência o uso de tecnologias de informação a serviço do monitoramento da cidade. A gestão da cidade, cada vez mais, depende que os dados sobre sua dinâmica possam ser sistematizados, avaliados e compreendidos de forma a gerar conhecimento para fundamentar ações de manutenção e planejamento. Transporte, prevenção de acidentes, segurança pública, iluminação, qualidade do ar, saneamento - são diversos os serviços que podem ser otimizados com esse monitoramento.

A administração da cidade, contudo, parece ora se orientar pelo panóptico de Bentham (2008), ora pela Sociedade de Controle de Deleuze (1992). De fato, é grande a diversidade de dados monitorados nas cidades brasileiras - notadamente nas grandes capitais. Na cidade do Rio de Janeiro, o Centro de Operações da Prefeitura mantém vigilância sobre diversos serviços, sem que no entanto as informações ali concentradas sejam facilmente acessadas pela população. Sendo mais preciso, os dados não estão disponíveis para serem manipulados; o que se dispõe são informações pré-formatadas em canais de acesso controlados pela própria prefeitura, sem que seja possível explorar o potencial de análise desses dados, ou propor novos modos de acessar essas informações (ROMAR, 2016). A administração pública controla totalmente o fluxo de informações. Que inteligência pode surgir nessa situação de total controle por parte do governo? Como comprovam Gaffney e Robertson (2016), um sistema de coleta de dados centralizado como o do Rio de Janeiro não é suficiente para qualificar a cidade como inteligente, a despeito de toda a propaganda de seus gestores vendendo essa imagem.

$\mathrm{Na}$ cidade inteligente a " inteligência " deveria ser construída organicamente, em sentido de baixo para cima, com participação de seus citadinos, aqueles que têm maior conhecimento sobre o dia-a-dia da cidade. É notável a iniciativa NYC Open Data ${ }^{1}$, em Nova York, através da qual dados sobre a cidade podem ser acessados pela população. O sítio funciona como um repositório de dados produzidos pelo governo, em formato próprio para leitura por máquinas ${ }^{2}$ e utilizando protocolos de comunicação que possibilitam sua utilização em aplicativos que se comunicam diretamente com a base de dados aberta. Segundo o próprio sítio web NYC Open data, o sistema é parte de uma iniciativa para melhorar a acessibilidade, transparência e prestação de contas do governo da cidade. Qualquer pessoa pode usar esses conjuntos de dados para participar e cobrar melhorarias do governo através da realização de pesquisas e análises ou a criação de aplicativos, obtendo assim uma melhor compreensão dos serviços prestados pelas agências do município.

É preciso promover uma mudança de visão do cidadão, de um papel passivo com pouca interferência nas questões urbanas, ao de parceiro na gestão da cidade. $O$ acesso livre e a possibilidade de manipulação dos dados podem favorecer o entendimento da dinâmica da cidade e incentivar o surgimento de soluções inovadoras, de baixo para cima. Entendendo melhor a

\footnotetext{
${ }^{1}$ https://opendata.cityofnewyork.us/

${ }^{2}$ Aqui nos referimos especificamente ao formato em que os dados são registrados digitalmente, o que tem relação direta com o tipo de arquivo de computador que será disposto ao público, bem como as possibilidades de operar com esses dados posteriormente. Existe uma diversidade de formatos, em função do tipo de informação a ser registrada. $\mathrm{O}$ ideal é que o formato utilizado seja passível de leitura por programas diversos, permitindo maior variedade de usos posteriormente. Cumpre lembrar que muitas vezes a leitura de bases de dados de cidades inteligentes é feita por máquinas, com programas que buscam informações e as aplicam em outros contextos, aplicativos etc.
} 
cidade, o citadino pode colaborar mais de perto na sua construção.

Esse entendimento sobre a cidade pressupõe a capacidade de visualizar dados relativos à dinâmica urbana. A cidade é uma sobreposição complexa de redes de serviços. Em paralelo a isso, a própria ação do homem na cidade gera rastros, marcas, registros em quantidade avassaladora. Esses registros podem ajudar a compreender a dinâmica da cidade como um organismo vivo, desde que haja uma preocupação em como apresentar esses dados. As tabelas, relatórios e gráficos normalmente utilizados não dão conta de representar essa dinâmica em sua totalidade, e não favorecem o entendimento do que está sendo representado.

Há uma diversidade de soluções possíveis para permitir o entendimento de dados sobre a cidade. De cartografias que dêem conta de mapear as dinâmicas urbanas, ao design de informação e infografias que permitam a manipulação intuitiva e visualização de dados complexos. Dentre esses possíveis caminhos, nos interessa especialmente investigar sistemas de informação que se apropriam dos conceitos de Tecnologia Calma propostos por Weiser e Brown (1997): os Sistemas de Informação Ambiente (PINHEIRO, 2010; PINHEIRO e SPITZ, 2011), uma categoria de sistemas de informação que apresentam dados sem exigir esforço, situando-se na periferia de nossa atenção. Nestes sistemas há uma preocupação especial em apresentar informações de forma discreta, sem que seja necessário interromper qualquer atividade para percebê-los.

Essa abordagem deve-se a dois fatores: primeiro para diminuir a dificuldade de entendimento das informações apresentadas, possibilitando uma macro-leitura sem esforço. Isso é particularmente importante se pretendemos atingir uma população não-especialista, composta majoritariamente por pessoas que não necessariamente dominam o conhecimento específico do assunto retratado. E segundo, porque acreditamos que essa abordagem com foco em " calma " ganha importância no contexto atual, em que vivemos em ambientes repletos de dispositivos e sistemas de informação que disputam nossa atenção a todo momento. $O$ aumento de fontes de informação na atualidade, a mobilidade dos dispositivos computacionais e o acesso quase ininterrupto às redes têm colaborado para o que $\operatorname{Hemp}(2008,2009)$ define como "sobrecarga de informação ". Por outro lado, percebe-se uma tendência na população dos grandes centros urbanos de procurar manter-se informado, uma necessidade de atualização constante, a despeito do sentimento de ansiedade que normalmente acompanha essas práticas (RICHTEL, 2010; WURMAN, 1991). Nesse sentido, acreditamos que sistemas de informação com o enfoque em calma, como propomos aqui, têm um papel estratégico para pesquisa e desenvolvimento de soluções que atendam às necessidades do modo de vida contemporâneo, sem no entanto sobrecarregar os indivíduos através de uma exposição cada vez mais intensa a sistemas de informação no seu cotidiano.

Neste artigo descrevemos o desenvolvimento dos primeiros protótipos de um sistema que visa apresentar informações sobre a qualidade do ar na cidade do Rio de Janeiro. O trabalho faz parte da pesquisa "Design de Sistemas de Informação Ambiente para Cidades Inteligente e Humanas, no contexto da Cidade do Rio de Janeiro ", desenvolvida na Escola Superior de Desenho Industrial (Esdi/Uerj) em 2016, com apoio da Fundação Carlos Chagas Filho de Amparo à Pesquisa do Estado do Rio de Janeiro (FAPERJ). O desenvolvimento do trabalho seguiu uma abordagem de projeto orientada pela experimentação e prototipagem (discutida anteriormente em CYPRIANO e PINHEIRO, 2015), mantendo ciclos sucessivos em que cada protótipo produzido é analisado criticamente, gerando subsídios para a versão seguinte. A seguir descreveremos os processos envolvidos, tecnologias empregadas, partidos adotados e resultados obtidos. 


\section{Desenvolvimento}

A partir da proposta de desenvolver novas formas de apresentação de dados sobre a cidade do Rio de Janeiro, o primeiro problema foi identificar quais informações seriam tratadas. A despeito de iniciativas como o Data $\mathrm{Rio}^{3}$, ainda é extremamente difícil encontrar dados atualizados sobre a cidade disponíveis em formatos que permitam a sua extração e manipulação posterior. ${ }^{4}$ Optamos, nesse primeiro momento, por buscar informações que estivessem disponíveis online, constantemente atualizadas, e que tivessem apelo à população, no sentido de que o assunto retratado tivesse um impacto direto em sua vida cotidiana. Dentre as opções pesquisadas, optouse por trabalhar com as informações relativas à qualidade do ar.

Desde 2008, a partir de um convênio entre a prefeitura do Rio de Janeiro e a Petrobras, foi implantado o Programa MonitorAr-Rio, cujo objetivo era reativar a rede municipal de monitoramento da qualidade do ar, inaugurada originalmente no ano 2000 . Além da reativação e complementação de antigas estações de monitoramento, houve a aquisição de quatro novas estações físicas, somando um total de oito estações e uma unidade móvel. Os dados coletados são dispostos em tabelas publicadas pela Secretaria Municipal de Conservação e Meio Ambiente, através da Subsecretaria de Meio Ambiente, no sítio eletrônico da Prefeitura ${ }^{5}$.

A qualidade do ar em diferentes bairros é expressa através da análise da quantidade de cinco poluentes ${ }^{6}$ - dióxido de enxofre $\left(\mathrm{SO}_{2}\right)$, monóxido de carbono (CO), material particulado $\left(\mathrm{MP}_{10}\right)$, ozônio $\left(\mathrm{O}_{3}\right)$ e dióxido de nitrogênio $\left(\mathrm{NO}_{2}\right)$, em amostras coletadas nas estações de monitoramento espalhadas pela cidade. O sítio do MonitorAr apresenta o boletim em tabelas como a da Figura 1.

A primeira dificuldade é compreender o que constituiu o Índice de Qualidade do $\operatorname{Ar}$ (IQA). Cada poluente analisado possui valores de referência, que indicam as faixas de valores que classificam a qualidade do ar como boa, regular, inadequada, má ou péssima, considerando apenas o poluente específico. O resultado do IQA é diretamente afetado pela classificação de qualquer um dos poluentes da análise. Convém destacar que nem todos os pontos de monitoramento fazem a medição dos cinco poluentes. No exemplo da Figura 1, podemos observar que no bairro de Irajá somente dois dos cinco poluentes que compõem o IQA foram analisados, o que não impediu que a qualidade do ar fosse considerada boa, a despeito de não haver informação sobre a quantidade de dióxido de enxofre, ozônio e dióxido de nitrogênio presentes no ar naquela localidade.

\footnotetext{
${ }^{3}$ Data.rio é um portal de dados abertos que dispõe informações relativas à cidade. O portal disponibiliza o acesso às informações do modal rodoviário municipal fornecidas pelo GPS instalados nos ônibus que circulam na cidade do Rio de Janeiro, dados sobre saúde, educação, reclamações ao 1746, entre outras. Apesar de mencionar que existem mais de mil dados disponíveis, grande parte das informações não são atualizadas desde 2013, e algumas sequer avançaram para além dos anos 90. Há diversos dados sobre espaços, equipamentos e mobiliário urbano - como por exemplo, localização dos monumentos e praças da cidade, estações do BRT, estações de trens da Supervia, estações de Metrô mas são dados que não demandam atualização constante e não refletem a dinâmica da cidade.

${ }^{4}$ A esse respeito, ver Gaffney e Robertson (2016).

${ }^{5}$ Boletim de Qualidade do Ar disponível no endereço <http://jeap.rio.rj.gov.br/je-metinfosmac/boletim>

${ }^{6}$ Convém destacar que não há um padrão único para medir a qualidade do ar. Como constatado por MEDEIROS (2011), apesar da existência de parâmetros reconhecidos internacionalmente, como o IAQ (index air quality) da Agência de Proteção Ambiental Americana, e o Global Air Quality Guidelines da Organização Mundial de Saúde, ao redor do mundo são usados diferentes classificações para a qualidade do ar.
} 
Figura 1 - Captura da tela do sítio do sistema MonitorAr, exibindo o boletim de qualidade do ar

\begin{tabular}{|c|c|c|c|c|c|c|c|c|}
\hline \multirow{3}{*}{$\begin{array}{l}\text { MonitorAR Rio } \\
\text { Programa de Monitoramento } \\
\text { da Qualidade do } \mathrm{Ar}\end{array}$} & \multirow{3}{*}{\multicolumn{2}{|c|}{ Secret }} & $\begin{array}{r}\text { REFEIT } \\
\text { taria M } \\
\text { Sı } \\
\text { B }\end{array}$ & $\begin{array}{l}\text { TURA D } \\
\text { lunicip } \\
\text { ubsecr } \\
\text { OLETI }\end{array}$ & $\begin{array}{l}\text { A CID } \\
\text { al de C } \\
\text { retaria } \\
\text { M DE C } \\
02 / 04 / \\
\text { Seg }\end{array}$ & $\begin{array}{l}\text { ADE D } \\
\text { Conser } \\
\text { de Me } \\
\text { QUALI } \\
201815 \\
\text { unda-feir }\end{array}$ & $\begin{array}{l}\text { O RIO D } \\
\text { vação e } \\
\text { eio Ambi } \\
\text { DADE D } \\
\text { :00h } \\
\text { ra }\end{array}$ & $\begin{array}{l}\text { DE JANEIRO } \\
\text { e Meio Ambiente } \\
\text { jiente } \\
\text { O AR }\end{array}$ \\
\hline & & & \multicolumn{5}{|c|}{ Exibir Boletim Anterior: } & \\
\hline & & & \multicolumn{3}{|r|}{ Data: } & \multicolumn{2}{|c|}{ Exibir } & \\
\hline \multirow[b]{2}{*}{ Estação } & \multicolumn{5}{|c|}{\begin{tabular}{|c|}
$\begin{array}{c}\text { Concentração Máxima } \\
\text { Poluentes Monitorados }\end{array}$ \\
\end{tabular}} & \multirow[b]{2}{*}{$\begin{array}{c}\text { Indice de } \\
\text { Qualidade } \\
\text { do Ar } \\
\text { (IQA) }\end{array}$} & \multirow{2}{*}{ Classificação } & \multirow{11}{*}{$\begin{array}{l}\text { Condições Meteorológicas observadas no período: } \\
\text { o deslocamento do sistema de alta pressão para o oceano } \\
\text { ocasionou céu com nebulosidade variada e ventos fracos a } \\
\text { moderados. Desta forma, observou-se o ligeiro declínio das } \\
\text { concentrações dos poluentes em relação ao dia anterior, em que a } \\
\text { qualidade do ar ficou classificada como REGULAR na maior parte } \\
\text { dos locais monitorados e, nas estações Irajá, Campo Grande e } \\
\text { Pedra de Guaratiba, BOA. } \\
\text { Tendência da Qualidade do Ar para as Próximas } 24 \mathrm{~h} \text { : } \\
\text { A aproximação de um sistema de baixa pressão pelo oceano } \\
\text { favorecerá variação de nebulosidade e possibilidade de chuva em } \\
\text { áreas isoladas do Município. Assim, espera-se a manutenção das } \\
\text { concentrações dos poluentes, O que deverá deixar a qualidade do } \\
\text { ar classificada como BOA e REGULAR nas localidades monitoradas. }\end{array}$} \\
\hline & \begin{tabular}{|c|} 
Dióxido de \\
Enxofre \\
$\left(\mathrm{SO}_{2}\right)$ \\
{$\left[\mathrm{gg} / \mathrm{m}^{3}\right](3)$}
\end{tabular} & \begin{tabular}{|c|}
$\begin{array}{c}\text { Monóxido } \\
\text { de Carbono } \\
\text { (CO) } \\
{[\mathrm{ppm}](2)}\end{array}$ \\
\end{tabular} & $\begin{array}{c}\text { Material } \\
\text { Particulado } \\
\text { (MP10) } \\
{\left[\mu \mathrm{g} / \mathrm{m}^{3}\right](3)}\end{array}$ & $\begin{array}{c}\text { Ozônio } \\
\left(O_{3}\right) \\
{\left[\mu g / m^{3}\right](1)}\end{array}$ & \begin{tabular}{|c|} 
Dióxido de \\
Nitrogênio \\
$\left(\mathrm{NO}_{2}\right)$ \\
{$\left[\mu \mathrm{g} / \mathrm{m}^{3}\right](1)$}
\end{tabular} & & & \\
\hline Centro & NM & 0,7 & 35,7 & $\underline{106,3}$ & NM & 67 & Regular & \\
\hline Copacabana & 8,3 & 0,2 & $\underline{59,3}$ & 53,1 & NM & 55 & Regular & \\
\hline São Cristóvão & 22,1 & 0,1 & 38,9 & $\underline{133,5}$ & NM & 84 & Regular & \\
\hline Tijuca & 7,9 & 0,6 & 30,1 & $\underline{96,1}$ & 83,3 & 60 & Regular & \\
\hline Irajá & ND & 0,5 & $\underline{49,8}$ & ND & ND & 50 & Boa & \\
\hline Bangu & 5,5 & 0,8 & 38,0 & $\underline{87,3}$ & 74,0 & 55 & Regular & \\
\hline Campo Grande & 2,5 & 0,5 & 31,3 & $\underline{74,3}$ & 65,7 & 46 & Boa & \\
\hline Pedra de Guaratiba & NM & NM & 40,4 & $\underline{75,9}$ & NM & 48 & Boa & \\
\hline Unidade Móvel Santa Cruz & ND & 0,1 & $\underline{70,7}$ & 69,8 & NM & 61 & Regular & \\
\hline \multirow{6}{*}{$\begin{array}{l}\text { Faixas de concentração dos } \\
\text { poluentes para cálculo do IQA }\end{array}$} & $\begin{array}{c}\left(\mathrm{SO}_{2}\right) \\
{\left[\mathrm{Hg} / \mathrm{m}^{3}\right](3)}\end{array}$ & $\underset{(p p m)(2)}{c o}$ & $\begin{array}{c}\mathrm{MP} 10 \\
\left(\mu g / m^{3}\right) \\
(3)\end{array}$ & $\begin{array}{c}O_{3} \\
\left(\mu g / m^{3}\right) \\
(1)\end{array}$ & $\begin{array}{c}\mathrm{NO}_{2} \\
\left(\mu \mathrm{g} / \mathrm{m}^{3}\right)(1) \\
\end{array}$ & \begin{tabular}{|c|} 
Indice de \\
Qualidade \\
do Ar (IQA)
\end{tabular} & Classificação & Significado da Classificação \\
\hline & $0-80$ & $0-4$ & $0-50$ & $0-80$ & $0-100$ & $0-50$ & BOA & Praticamente não há riscos à saúde. \\
\hline & $81-365$ & $4,1-9$ & $51-150$ & $81-160$ & $101-320$ & $51-100$ & REGULAR & $\begin{array}{l}\text { Pessoas de grupos sensiveis podem apresentar tosse seca e cansaço. A } \\
\text { população, em geral, não é afetada. }\end{array}$ \\
\hline & $366-800$ & $9,1-15$ & $151-250$ & $161 \cdot 200$ & $321-1130$ & $101-199$ & INADEQUADA & $\begin{array}{l}\text { Toda a população pode apresentar sintomas como tosse seca, cansaço, } \\
\text { ardor nos olhos, nariz e garganta. Pessoas de grupos sensiveis podem } \\
\text { apresentar efeitos mais sérios na saúde. }\end{array}$ \\
\hline & $801-1600$ & $15,1-30$ & $251-420$ & $201-800$ & $\begin{array}{l}1131- \\
2260\end{array}$ & $200-299$ & MÁ & $\begin{array}{l}\text { Toda a população pode apresentar agravamento dos sintomas como tosse } \\
\text { seca, cansaço, ardor nos ollhos, nariz e garganta e ainda apresentar falta de } \\
\text { ar e respiraçăao ofegante. Efeitos mais graves à saúde de grupos sensiveis. }\end{array}$ \\
\hline & $\begin{array}{l}1601- \\
2100\end{array}$ & $30,1-40$ & $421-500$ & $801-1000$ & $\begin{array}{c}2261- \\
3000\end{array}$ & $>300$ & PÉSSIMA & $\begin{array}{l}\text { Toda a população pode apresentar sérios riscos de manifestações de } \\
\text { doenças respiratórias e cardiovasculares. Aumento de mortes prematuras } \\
\text { em pessoas de grupos sensiveis }\end{array}$ \\
\hline
\end{tabular}

Mais informações sobre o IQA Entenda melhor sobre o Boletim de Qualidade do Ar

Fonte: http://jeap.rio.rj.gov.br/je-metinfosmac/boletim (2018)

A escolha por uma tabela para apresentar as informações sobre a concentração de cada poluente não facilita o entendimento do que efetivamente ocorre no ambiente. De modo semelhante, as variações das grandezas numéricas ao longo do tempo não são facilmente percebidas. A visualidade da tabela não favorece a percepção intuitiva dos dados, demandando uma análise mais detalhada, seja para apreender as informações de um dia específico, seja para comparar dias distintos ao longo de um período. A opção por uma escala cromática para representar a classificação do IQA de cada bairro e a utilização do negrito para apresentar o poluente com maior valor - e consequentemente o principal responsável pelo IQA - facilitam a leitura geral, mas não são suficientes para tornar a visualização da informação mais intuitiva ou atraente para pessoas não familiarizadas com essa temática.

\subsection{Primeiro protótipo}

As dificuldades em interpretar a tabela foram o ponto de partida para a explorar novas formas de visualização de dados, que pudessem representar o IQA com menor carga informacional. A intenção era possibilitar uma leitura rápida, intuitiva, reduzindo o nível de 
detalhes da representação mas preservando a possibilidade de percepção da qualidade do ar. Ao fim e ao cabo, interessava principalmente promover a discussão sobre a qualidade do ar. Nesse sentido, optamos por não trabalhar diretamente com o IQA e nem evidenciar a classificação da qualidade oferecida pelo MonitorAr-Rio, permitindo com que o próprio usuário julgasse o ar como próprio ou impróprio a partir da informação apreendida.

Começamos a esboçar alternativas para a representação da qualidade do ar, partindo de uma abordagem de fácil associação: a visualização de partículas num espaço determinado, representando os poluentes dispersos no ar. Quanto maior a quantidade de partículas, maior a concentração de poluentes monitorados e, consequentemente, pior a qualidade do ar. Para verificar a eficiência dessa visualização, representamos cada possibilidade de classificação do IQA previsto nos boletins do MonitorAr-Rio: boa, regular, inadequada, má e péssima. A representação foi feita utilizando a linguagem de programação Processing ${ }^{7}$, produzindo nuvens de partículas dentro de um espaço delimitado, para cada uma das gradações previstas (Figura 2). A quantidade de pontos utilizada a princípio era arbitrária, não havendo relação numérica com a faixa de concentração dos poluentes para cálculo do IQA apresentada no site da prefeitura. A intenção deste primeiro modelo era apenas testar o conceito de uma "nuvem " de partículas como representação de diferentes estados da qualidade do ar. O protótipo pode ser visto no endereço: $<$ http://bit.ly/visualizacao01>.

Figura 2 - Captura de tela do primeiro protótipo, com representações de diferentes concentrações de $\mathrm{SO}_{2}$

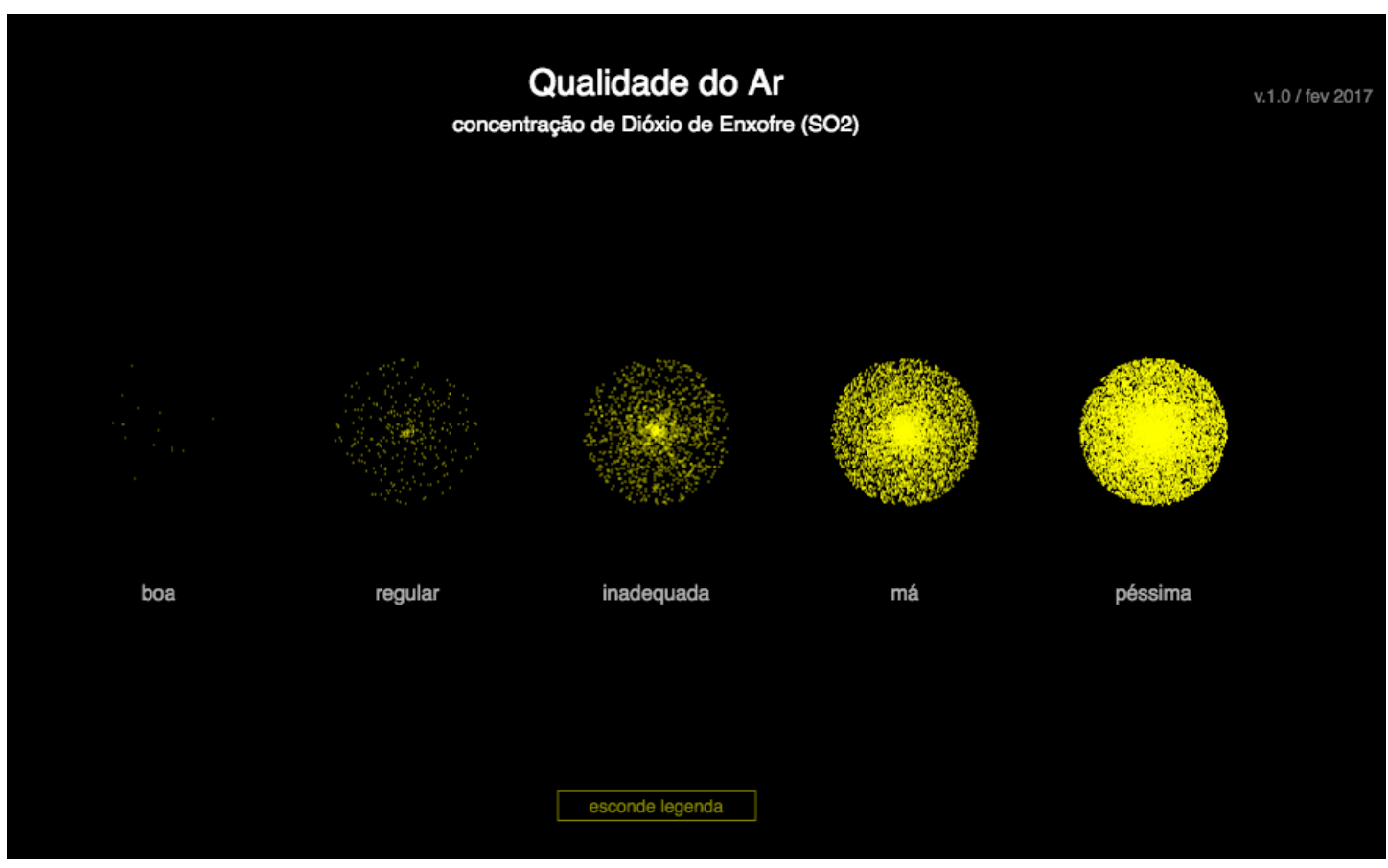

Fonte: os autores - http://bit.ly/visualizacao01 (2017)

\footnotetext{
${ }^{7}$ Processing é uma linguagem de programação desenvolvida em 2001 por Ben Fry e Casey Reas, durante seu mestrado no MIT Media Lab, como participantes do grupo de pesquisa Aesthetics and Computation, de John Maeda. O objetivo era ter uma linguagem própria para o ensino de design computacional. Graças à sua facilidade de uso e por ser um programa de código aberto, atualmente é utilizada por artistas e designers de todo o mundo. Seu desenvolvimento foi continuado pela comunidade entusiasta que se formou a partir do seu lançamento.
} 


\subsection{Segundo protótipo}

A partir do primeiro protótipo, foi possível perceber que o princípio elementar era facilmente compreendido: quanto mais partículas, maior a poluição e pior a qualidade do ar. Como mencionado anteriormente, não havia uma preocupação inicial em apresentar dados exatos, mas possibilitar a compreensão intuitiva da situação representada. Abordagem semelhante foi utilizada por Medeiros (2011) em sua instalação sobre a qualidade do ar, na qual " nuvens » de material sintético presas ao teto de um cômodo representavam diferentes capitais ao redor do mundo, mudando de cor de acordo com o índice de qualidade do ar na cidade representada. No entanto, em seu trabalho o autor optou por utilizar somente o índice, sem representar os componentes que geraram aquele resultado. Acreditamos que essa distinção é importante, porque possibilitaria uma discussão sobre os motivos de determinado poluente ter uma presença mais expressiva em determinada localidade.

Assim, no segundo protótipo procuramos representar os diferentes poluentes monitorados que interferem na classificação da qualidade do ar. Mantendo a metáfora da nuvem de partículas, para cada poluente foi atribuída uma cor, tendo o cuidado de selecionar matizes e relações de brilho e saturação que permitissem distinguir as cores umas das outras. A nuvem multicolorida representava a concentração dos cinco poluentes em uma determinada região da cidade (Figura 3). Nesse protótipo, também realizado em Processing, cada partícula movimentava-se de modo independente, resultando em uma dinâmica visual maior, facilitando a percepção dos poluentes isolados. Para agilizar a produção do protótipo, os índices dos poluentes ainda eram arbitrários, e em alguns casos propositalmente exagerados, para verificar como a visualização se comportaria nos casos extremos. O protótipo pode ser visto em <http://bit.ly/visualizacao02>.

Figura 3 - Captura de tela do segundo protótipo, com representações de diferentes bairros, cada um com concentrações variadas dos cinco poluentes monitorados

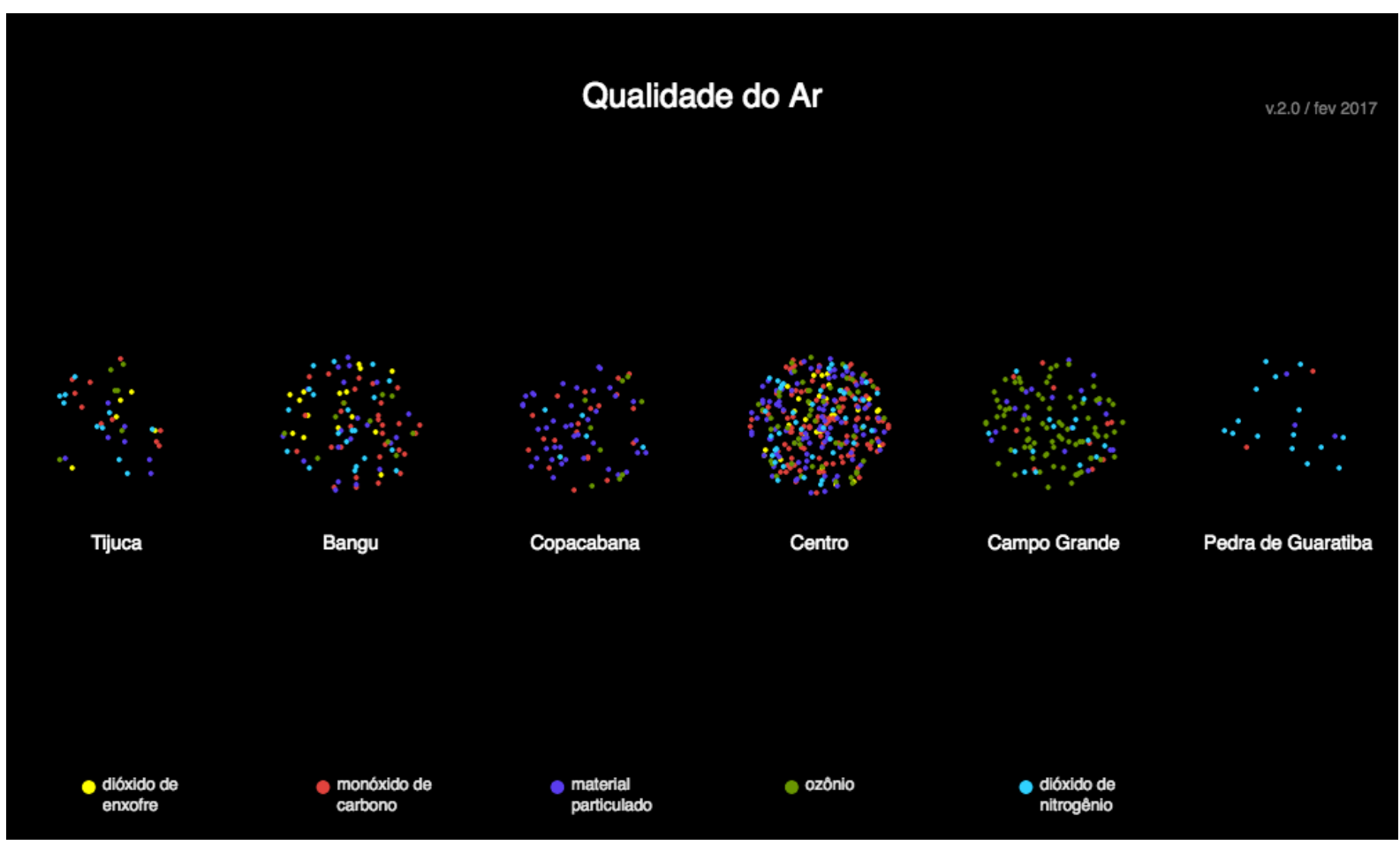

Fonte: os autores - http://bit.ly/visualizacao02 (2017) 
Essa visualização faz uso apropriado dos princípios dos Sistemas de Informação Ambiente, conforme definidos em Pinheiro e Spitz (2011): apresenta dados de maneira mais abrangente, trabalhando com nível de detalhamento baixo de modo a não sobrecarregar o usuário com excesso de informação; procura utilizar uma metáfora que pode ser facilmente apreendida, e uma vez compreendida é passível de habituação, isto é, não demanda esforço para sua apreensão; privilegia uma percepção intuitiva das informações, envolvendo poucos recursos atencionais.

\subsection{Terceiro protótipo}

Após essa etapa, passamos a preparar uma versão capaz de ler diretamente os dados das tabelas disponibilizadas no sítio do MonitorAr. Infelizmente, o sítio não dispõe os dados em formato próprio para ser utilizado diretamente por outros programas ${ }^{8}$, tampouco dispõe de uma $\mathrm{API}^{9}$ para facilitar a comunicação entre sistemas. Como não havia na equipe alguém com expertise suficiente para desenvolver um programa que extraísse os dados diretamente do sítio e tratasseos de modo a torná-los aptos à utilização no Processing, optamos nesse primeiro momento por copiar os relatórios diretamente do sítio e preparar manualmente versões das tabelas, de modo a possibilitar sua leitura pelo programa. Em versões futuras, para viabilizar a atualização automática do sistema com os boletins mais recentes, seria necessário desenvolver um programa específico para capturar os dados diretamente do código HTML do sítio da Prefeitura e tratá-los de modo a gerar uma versão em formato que possa ser utilizada pelo Processing.

Uma vez convertidas as tabelas com boletins de 2015, 2016 e 2017, desenvolvemos um terceiro protótipo que representaria efetivamente os dados coletados nos períodos selecionados. Havia, contudo, uma questão inicial a ser resolvida: as faixas relativas à concentração máxima tolerada para cada poluente que compõe o IQA seguem escalas muito distintas quando comparadas entre si. Os valores da faixa considerada " boa » para o monóxido de carbono vão de 0 a 4, e da faixa " péssima " vão de 30,1 a 40; Já os valores da faixa " boa " para o dióxido de nitrogênio vão de 0 a 100, e da faixa " péssima " vão de 2261 a 3000. Além da discrepância de valores, cada componente variava com uma progressão distinta: ao lançarmos os valores relativos ao mínimo e máximo de cada faixa de classificação do IQA por poluente, criarmos um gráfico no qual foi possível constatar o crescimento irregular entre os valores de referência de cada poluente (Figura 4).

\footnotetext{
${ }^{8}$ Como mencionado anteriormente, existem formatos que facilitam a comunicação entre sistemas distintos, e que possibilitam que um aplicativo consiga ler informações publicadas em um sítio eletrônico. Entre esses formatos podemos citar XML (Extensible Markup Language), JSON (JavaScript Object Notation) ou mesmo CSV (comma separated value) - os dois primeiros formatos permitem maior descrição e categorização dos dados, facilitando sua identificação e utilização posterior. No caso dos boletins com qualidade do ar publicados pelo MonitorAr, as informações estão unicamente em HTML, com tabelas que não seguem os padrões de acessibilidade da W3C, que regulamentam as boas práticas de documentação para web. Isso dificulta sobremaneira a automatização da leitura dessas informações.

${ }^{9}$ API é a sigla para Application Programming Interface, ou Interface de Programação de Aplicativos, isto é, um protocolo que possibilita a comunicação entre uma base de dados de um sítio ou serviço online, e aplicativos externos. Redes sociais como Twitter e Facebook, e serviços online com Google Maps, dispõem de APIs, que possibilitam que seus dados sejam acessados diretamente por aplicativos desenvolvidos por terceiros.
} 


\section{Artigo Completo}

Figura 4 - Gráfico evidenciando a progressão irregular entre as faixas de classificação da qualidade do ar, para cada poluente monitorado, de acordo com os valores padrão do IQA.

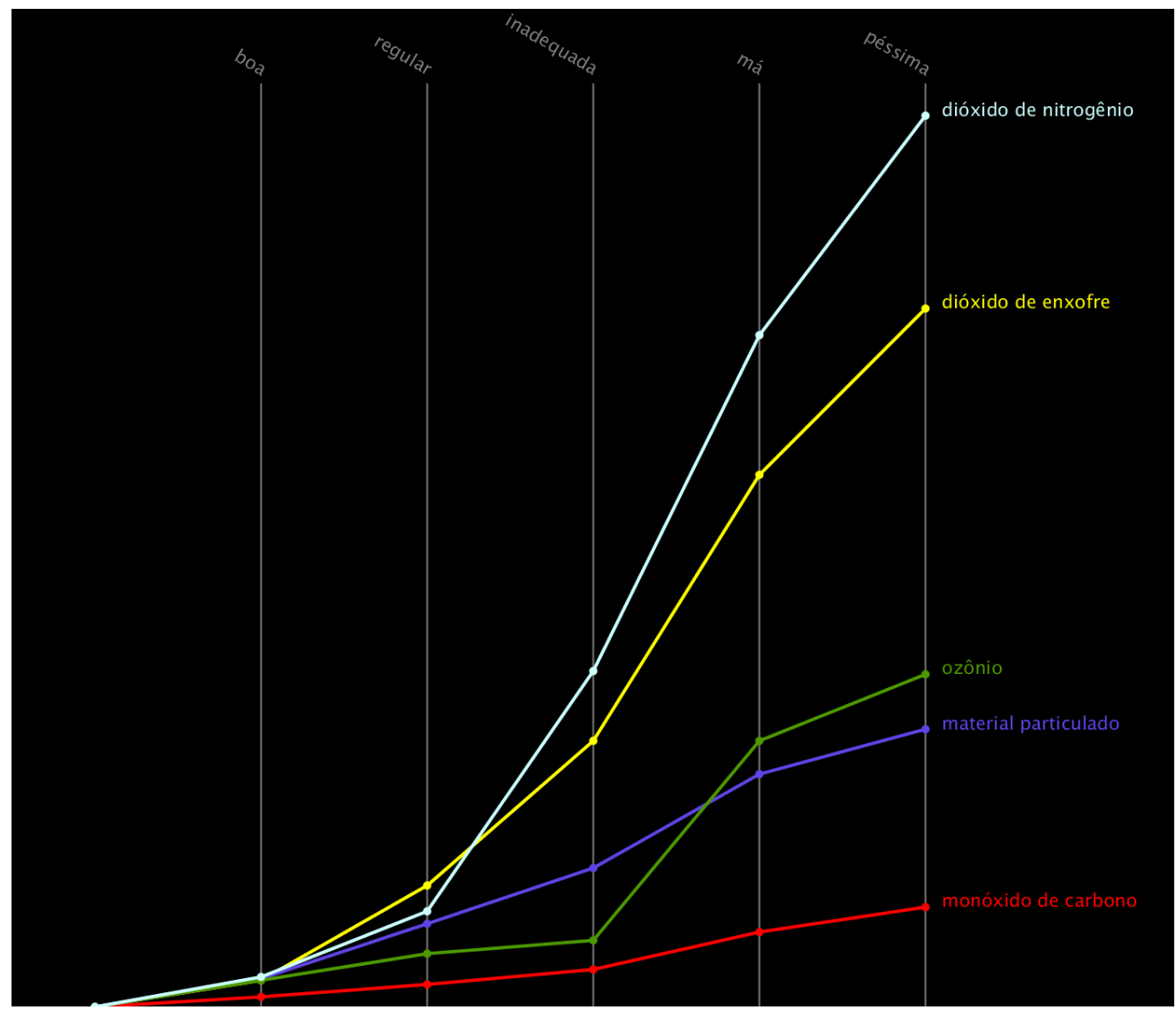

Fonte: os autores (2017)

Essa discrepância indicava que não seria interessante estabelecer uma relação direta entre os números brutos e a quantidade de partículas a serem desenhadas na visualização. Considerando que a proposta era possibilitar o entendimento intuitivo sobre a qualidade do ar, expressa pela maior ou menor concentração de poluentes, entendemos que não seria necessário apresentar uma representação exata da quantidade de poluentes; a chave foi evidenciar as faixas de classificação (boa, regular, má, inadequada e péssima). Optamos por equalizar os valores entre os poluentes, de modo que todos passassem a operar dentro da mesma escala. A conversão era feita diretamente pelo Processing, que lia os valores originais contidos nos boletins, e operava as alterações de acordo com as regras estabelecidas para cada poluente.

Para evidenciar graficamente as diferentes faixas de classificação do IQA, fizemos com que a quantidade de partículas crescesse exponencialmente: quanto pior o cenário, mais drástica é a representação gráfica. Desse modo, a escala comum que passamos a adotar para os poluentes vai de 0 a 1024, representada por uma curva exponencial.

O protótipo da última versão da visualização incorporava essas mudanças: partia de tabelas com os dados brutos originais, convertidos em formato próprio para leitura pelo Processing; operava uma equalização das diferentes escalas de valores dos cinco poluentes monitorados; convertia os valores de modo a acentuar a dramaticidade, pelo aumento exponencial da quantidade de partículas representadas quanto pior fosse a situação de poluição do ar (Figura 5). Além disso, 
nessa versão incorporamos um botão que permite selecionar a visualização de mais de um boletim, possibilitando a comparação entre dias diferentes. Dessa forma, esperamos potencializar discussões pela possibilidade de verificar a evolução da qualidade do ar ao longo do tempo. Neste protótipo apenas três boletins foram colocados à disposição. A futuro, a intenção é permitir a navegação por toda a série histórica. Finalmente, apesar da intenção de trabalhar apenas com a visualização intuitiva, que não implique na análise detalhada dos dados, incluímos a possibilidade de acessar os valores exatos do boletim, posicionando o ponteiro do mouse sobre a nuvem de partículas de cada bairro. Dessa forma, é possível alternar os modos de engajamento: de uma posição mais contemplativa e exploratória para uma mais compenetrada e analítica. O protótipo em movimento pode ser visto em <http://bit.ly/visualizacao03>.

Figura 5 - Captura de tela do terceiro protótipo, com dados normalizados e possibilidade de navegação entre boletins.

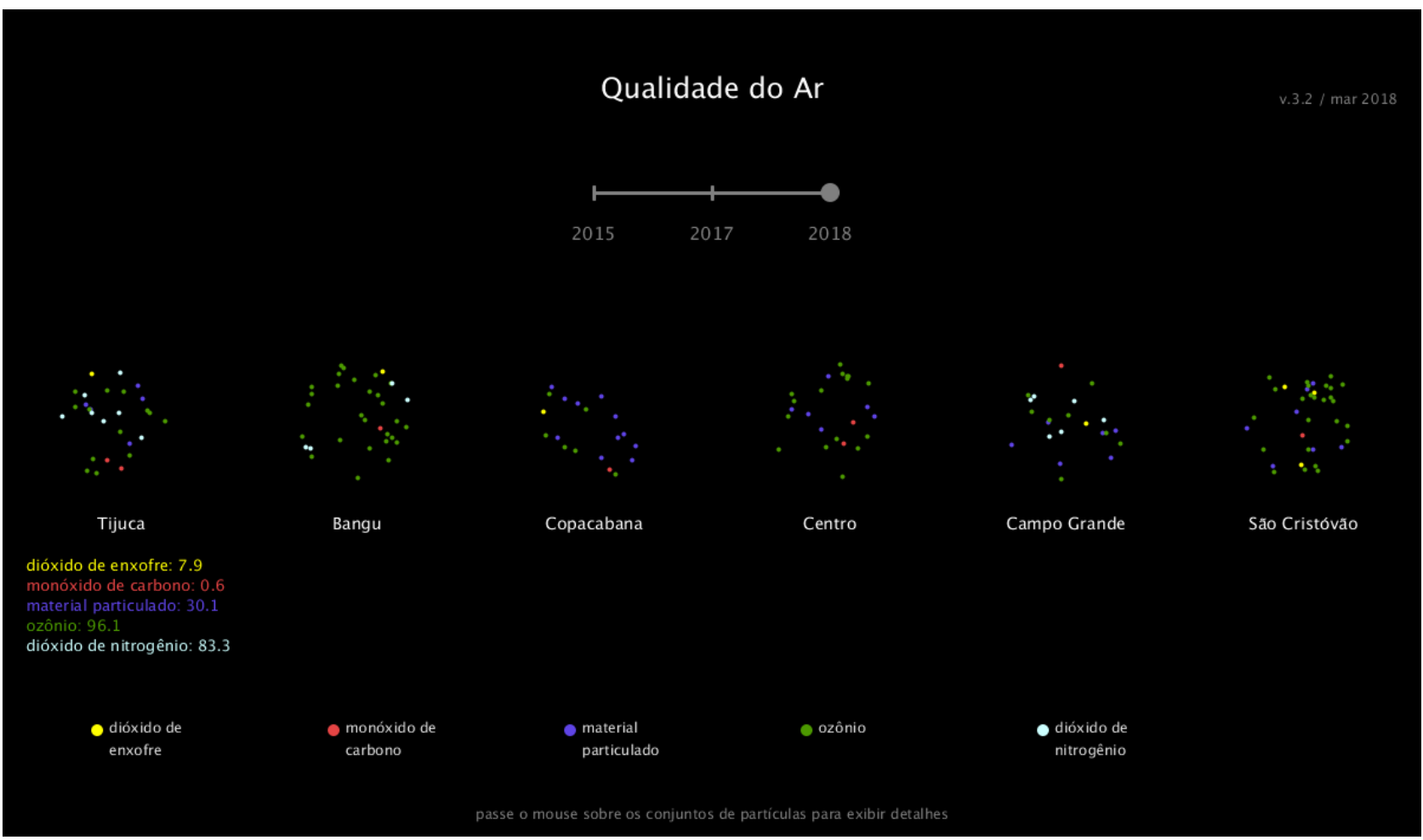

Fonte: os autores - http://bit.ly/visualizacao03 (2018)

\section{Discussão}

O protótipo apresentado resolve parte das questões iniciais levantadas, apresentando os dados de maneira lúdica e sintética, permitindo a percepção e entendimento geral do Índice de Qualidade do Ar. Acreditamos que o resultado alcançado facilita o compreensão das informações originalmente dispostas nas tabelas pouco amigáveis dos boletins do programa MonitorAr da Prefeitura do Rio de Janeiro, potencializando a discussão sobre a qualidade do ar nas regiões representadas. Contudo, resta a dúvida quanto a eficácia do sistema nos casos em que seja de interesse do usuário a leitura precisa das informações. Em que pese o fato da abordagem utilizada, baseada nos princípios do Tecnologia Calma e em Sistemas de Informação Ambiente, não ser adequada para veicular informações com muitos detalhes, procuramos oferecer o acesso aos dados completos sobre os poluentes em cada boletim, para os bairros retratados. Todavia, a 
incongruência entre os valores nas suas escalas originais e a representação normalizada utilizada na visualização pode causar estranheza, fato este que mereceria ainda um estudo específico.

Cumpre registrar que no período compreendido pela pesquisa, em função da crise do Estado do Rio de Janeiro ter afetado diretamente a universidade que sediou este trabalho, bem como a fundação de amparo à pesquisa que financiava o estudo, não foi possível conduzir testes com usuários para verificar a pertinência e eficácia das escolhas realizadas. De todo modo, acreditamos que os resultados alcançados são originais e respondem à proposta inicial de maneira adequada e criativa.

\section{Considerações finais}

O aumento de fontes de informação e acesso quase ininterrupto a dispositivos de comunicação e conexão têm colaborado para uma sensação de sobrecarga informacional. Levando em consideração a reconfiguração das cidades em direção às cidades inteligentes, temos em perspectiva o agravamento desse quadro, com a integração de sistemas de coleta, processamento e exibição de dados em diferentes suportes e espaços cotidianos. Ao mesmo tempo, conforme discutimos em outra oportunidade (PINHEIRO, 2017), as cidades inteligentes correm o risco de auxiliar a perpetuação de estruturas de controle dos grupos hegemônicos que operam os mecanismos político-econômicos. É preciso promover o engajamento do cidadão na discussão sobre o desenho da cidade, especialmente considerando o acesso cada vez mais facilitado aos meios tecnológicos e a democratização das ferramentas de criação, comunicação e publicação, bem como a possibilidade de acesso a um volume de dados crescente sobre essas mesmas cidades. Nossa visão sobre a importância de potencializar processos de participação da população na gestão da cidade alinha-se com o que De Waal (2014) classifica como uma visão de cidade republicana, ao comparar diferentes discursos sobre cidades inteligentes. A cidade republicana (de res publica, coisa pública) se baseia na ideia de que os cidadãos dividem a responsabilidade sobre a cidade e há um senso de inserção e participação do indivíduo na vida pública.

Contudo, a possibilidade de participação nas questões urbanas dependerá, entre outros fatores, do entendimento das informações complexas geradas dinamicamente no fluxo de redes que se sobrepõem. Nesse cenário, ganha importância a visualização de dados, especialmente quando alinhada aos princípios da Tecnologia Calma e dos Sistemas de Informação Ambiente. É preciso usar a criatividade para desenvolver soluções que permitam informar sem sobrecarregar, sem demandar atenção para si, aproveitando-se da intuição, explorando aspetos estéticos e lúdicos que promovam encantamento e despertem o interesse.

O trabalho aqui apresentado constitui uma exploração sobre esse tema, valendo-se de uma metodologia baseada em ciclos de prototipação rápida, num processo de evolução incremental. De modo semelhante, os resultados alcançados sugerem novos desdobramentos. A futuro, pretende-se adaptar os princípios aqui desenvolvidos para a criação de uma instalação urbana, um Sistema de Informação Ambiente que permeie a própria urbe e possa ser visto pela população em meio às atividades cotidianas. A discussão sobre a cidade potencializada pela visualização de dados sobre si mesma, em pleno contexto urbano. 


\section{Agradecimentos}

Agradecemos à Fundação Carlos Chagas Filho de Amparo à Pesquisa do Estado do Rio de Janeiro e à Universidade do Estado do Rio de Janeiro, pela bolsas de pesquisa que viabilizaram este trabalho.

\section{Referências}

BENTHAM, Jeremy. O panóptico. 2. ed. Belo Horizonte: Autêntica Editora, 2008.

CYPRIANO, Lucas O.; PINHEIRO, Mauro. Prototyping and Testing Throughout all the Design Process as a Methodology for Developing Interaction Design Projects. In: Aaron Marcus. (Org.). Design, User Experience, and Usability: Design Discourse. Springer, 2015, v. 1, p. 157-166.

DELEUZE, Gilles. Post-scriptum sobre as sociedades de controle. In: Conversações, 1972-1990. Rio de Janeiro: Editora 34, 1992. p.219-226.

DE WAAL, Martjin. The city as interface: how new media are changing the city. Rotterdam: nai010 publishers, 2014.

GAFFNEY, Christopher; ROBERTSON, Cerianne. Smarter than smart: Rio de Janeiro's flawed emergence as a smart city. Journal of urban technology, p. 1-18, 29 abr. 2016. Disponível em: <http://dx.doi.org/10.1080/10630732.2015.1102423>. Acesso em: 20 set. 2016.

HEMP, Paul. Death by information overload. Harvard Business Review, set. 2009. . What's So Bad About Information Overload? Harvard Business Review, 27 jun. 2008.

MEDEIROS, Rodrigo Pessoa. WARNING - Real Time Global Air Quality Display: possibilidades de criação de visualização de informação com tecnologias livres. In: Interaction South America, 2011, Belo Horizonte. Anais da 3a Conferência Latino-Americana de Design de Interação. Belo Horizonte: IxDA, 2011. v. 1. p. 214-224.

PINHEIRO, Mauro. Designing for the periphery of our attention: a study on Ambient Information Systems. In: DRS 2010 Design Research Society International Conference, 2010, Montréal; Proceedings...CD-ROM. Montréal, 2010.

PINHEIRO, Mauro; SPITZ, Rejane (Orientadora). Design de interação e computação pervasiva: um estudo sobre mecanismos atencionais e sistemas de informação ambiente. Rio de Janeiro, 2011. 212p. Tese de Doutorado - Departamento de Artes e Design, Pontifícia Universidade Católica do Rio de Janeiro.

PINHEIRO, Mauro. Sistemas Informação Ambiente: leitura e engajamento nas Cidades Inteligentes. In: CAMARA, Rogério; SANTOS, Fátima Aparecida dos. Urbanidades: mediações. Brasília: Estereográfica, 2017, pp. 93-115.

RICHTEL, Matt. Attached to technology and paying a price. The New York Times, New York, 6 jun. 2010. Disponível em: <http://www.nytimes.com/2010/06/07/technology/07brain.html>. Acesso em 3 abr 2018.

ROMAR, Juliana. Prefeitura apresenta as instalações do Centro de Operações Rio, considerado o mais moderno do mundo. Disponível em: <http://www.rio.rj.gov.br/web/guest/exibeconteudo?article- 
id=1410657>. Acesso em 20 set. 2016.

WEISER, Mark; BROWN, John Seely. The coming age of calm technology. In: DENNING, Peter J.; METCALFE, Robert M. (orgs). Beyond Calculation: The Next Fifty Years of Computing. New York: Springer, 1997. Disponível em: <https://doi.org/10.1007/978-1-4612-0685-9_6>. Acesso em: 3 abr 2018. WURMAN, Richard Saul. Ansiedade de informação: como transformar informação em compreensão. São Paulo: Cultura Editores Associados, 1991. 